\title{
Depression among predictors of intermittent claudication: A cross-sectional study
}

\section{GERGELY TÓTH-VAJNA ${ }^{1 *}$ (1), ZSOMBOR TÓTH-VAJNA² ㄹ, BARNA KONKOLY THEGE ${ }^{3,4}$ (1) and PIROSKA BALOG ${ }^{1}$}

\author{
${ }^{1}$ Institute of Behavioral Sciences, Semmelweis University, Budapest, Hungary \\ ${ }^{2}$ Heart and Vascular Center, Department of Vascular Surgery, Semmelweis University, Budapest, \\ Hungary \\ ${ }^{3}$ Waypoint Research Institute, Waypoint Centre for Mental Health Care, Penetanguishene, Ontario, \\ Canada \\ ${ }^{4}$ Department of Psychiatry, University of Toronto, Toronto, Ontario, Canada
}

Received: March 15, 2020 • Accepted: September 12, 2021

Published online: October 14, 2021

(c) 2021 The Author(s)

\begin{abstract}
Purpose: The aim of the present cross-sectional study was to investigate the relationship between depression and intermittent claudication (IC), independently of traditional risk factors. Main methods: The sample consisted of 300 individuals $\left(M_{\text {age }}=65.3 \pm 8.7\right.$ years, $61.0 \%$ female) recruited from the offices of 33 general practitioners. Participants' medical history and the presence of major cardiovascular risk factors were recorded. Participants completed the Edinburgh Claudication Questionnaire. The role of depression (assessed by a shortened version of the Beck Depression Inventory) in predicting IC was examined using a binary logistic regression analysis - controlled for sex, age, hypertonia, diabetes, smoking, hypercholesterinemia, hazardous drinking, and body mass index (BMI). Results: The descriptive data indicated that the prevalence of depression was $57.9 \%$ in the IC subgroup and $16.1 \%$ in those free of IC. The bivariate analyses indicated that hypercholesterinemia, smoking, hazardous drinking, BMI, and depression were significantly associated with IC. Male sex and age showed a trend toward being a significant correlate of IC. Results of the multivariate analyses indicated that depressive symptomatology was significant in predicting IC (OR: 1.08 (1.05-1.11)), even after controlling for lifestyle and traditional risk factors such as smoking, hazardous drinking, and BMI. Among traditional risk factors, smoking (OR: 2.44 (1.26-4.74)), hazardous drinking (OR: 1.19 (1.02-1.40)), and hypercholesterinemia (OR: 2.17 (1.26-3.75)) showed a significant,
\end{abstract}

\footnotetext{
* Corresponding author. Institute of Behavioral Sciences, Semmelweis University, Nagyvárad tér 4, Budapest, 1089 Hungary. Tel.: +36 309021050; fax: +36 12102955. E-mail: toth-vajna.gergely@med.semmelweis-univ.hu, tothgeri@gmail.com
} 
positive relationship with IC. Conclusions: These results underscore the importance of a multidisciplinary approach that focuses on supporting health-related behavioral changes and managing mental health symptoms when providing care for patients with IC.

\section{KEYWORDS}

intermittent claudication, lower extremity arterial disease, peripheral arterial disease, depression, vascular disease

\section{INTRODUCTION}

Intermittent claudication (IC) is the most characteristic symptom of LEAD (lower extremity arterial disease), that contributes to the presence of limping in affected patients. Characteristics are the recurrence and localization of the pain and its cease after rest. After certain physical activities, pain appears in the lower extremities, which intensifies with exercise time and intensity, forcing the patient to limp, and eventually impeding their ability to walk. Intermittent claudication usually disappears fast, i.e. after $10 \mathrm{~min}$ of rest. Based on the localization and size of the stenosis, IC can occur in different parts of the lower extremities. Most common anatomical locations are the calf, gluteal muscles, and the thigh, and is least common in the feet [1].

LEAD affects more than 202 million individuals worldwide, from which 40 million are European [2]. The number of patients with LEAD has increased by $23 \%$ in the last decade, due to population growth, ageing and diabetes; however, smoking remains the main risk factor in middle- and low-income countries [3]. The majority of patients are asymptomatic thus LEAD remains undiscovered and untreated without special screening [4]. These patients have a $20 \%$ higher risk of experiencing a cerebrovascular event, which highlights the system-disease nature of LEAD [5]. Traditional risk factors of LEAD include hypertension, diabetes, smoking, and hyperlipidemia; however, the implications of psychological aspects and their roles in the pathogenesis of LEAD [6] are now being considered. For instance, among patients with IC, symptoms of depression have been identified as a personal barrier to exercise [7].

The results regarding a depression-LEAD association are contrasting: some studies report a significant correlation between depression and limb symptoms [8] or walking ability [9] while others [10] report that adjusting for these two variables attenuated the association. Therefore, the aim of the present study was to analyze the predictive role of depressive symptomatology in IC independently of its established risk factors such as hypertension, diabetes, hypercholesterinemia, drinking, smoking, and body mass index.

\section{MATERIALS AND METHODS}

\section{Participants and procedure}

The study was approved by the Scientific and Research Ethics Committee of the Medical Research Council, Semmelweis University (ETT TUKEB 285/2015) and was carried out in accordance with the tenets of the Declaration of Helsinki. Data collection took place between November 2015 and February 2018, with participants recruited from the practices of 33 general practitioners from across Hungary. 
LEAD usually appears after the age of 50 years, with an exponential increase after the age of 65 years. According to governmental regulations of the country of study, it is obligatory to screen patients for the presence and symptoms of LEAD every two years after the age of 45; therefore, the target population included men and women aged 45 or older with at least one major vascular risk factor (current smoking, type 2 diabetes, or hypertension). Altogether, 300 (Mage $=65.3$ years, $\mathrm{SD}=8.7$ years; $61.0 \%$ female) individuals agreed to participate in the present study, of which all were provided written informed consent.

Participants' medical history and the presence of major cardiovascular risk factors were recorded based on the health records maintained by their general practitioners. The inperson examination started with the completion of the Edinburgh Claudication Questionnaire (ECQ). The questionnaire - consisting of 6 items - is a validated and frequently used method for screening intermittent claudication. It requires yes-or-no type answers for all questions and the localization of pain. The definite claudicant indicates pain in the calf, or in the thigh or buttock in the absence of any calf pain. Subjects should not be considered to have claudication if pain is indicated in the hamstrings, feet, shins, joints, or appears to radiate, in the absence of any pain in the calf. The Questionnaire has a sensitivity of over $80-90 \%$ and a specificity of over 95\% [11].

Second, the basic body measurements (height and weight) were collected. BMI (Body Mass Index) was calculated by using patients' height and body weight measured at the screening with a validated measure. Respondents were considered smokers if they indicated active smoking during the recording of their medical history. Patients who had a diagnosis of diabetes, hypertension, and hypercholesterinemia in their medical records were considered positive for these conditions.

\section{Psychological instruments}

Depressive symptoms were measured with the shortened Hungarian version of the Beck Depression Inventory (BDI), a 9-item questionnaire to assess depression severity [12]. Each item is scored on a 4-point scale ranging from 0 (not at all characteristics of me) to 3 (very characteristic of me). Internal consistency of the scale proved to be strong in the current sample (Cronbach's $\alpha=0.86$ ). To allow international comparability, the total score of the 9-item version was transformed to align with the 21 -item original version by multiplying the total scores by 2.33. The cut off score indicating the presence of at least mild depression was therefore identical to that in the international literature $(\geq 10)$.

Hazardous drinking was measured with the alcohol consumption questions of the AUDIT (AUDIT-C) [13]. This is a 3-item tool for the screening of hazardous drinking habits. Each question is scored on a scale ranging from 0 to 4 . Four points or above in men, 3 points or above in women are indicative of hazardous drinking. The advantage of the shortened version is its ease of use in primary care. Internal consistency in the current sample was strong (Cronbach's $\alpha$ $=0.84)$.

\section{Statistical analyses}

When investigating the relationship between IC and continuous variables, an independent sample $t$-test was conducted (Cohen's $d$ was used to express effect size). When examining the association between the dependent variable and the categorical independent variables, the chi square test was employed (Cramer's V was reported to express effect size). On the multivariate 
level, a binary logistic regression analysis was conducted to investigate the role of all independent variables in differentiating between patients with and without IC. There were no missing data in the data set. All the above analyses were carried out using the Statistical Package for the Social Sciences, Version 27 (IBM SPSS, 2021).

\section{RESULTS}

The descriptive data indicated that the prevalence of (mild, moderate, or severe) depression was $57.9 \%$ in the IC subgroup and $16.1 \%$ in those free of IC. The results of the bivariate analyses indicated that the relationship between depression and IC is strong: the mean of depressive symptoms in the IC subgroup was 14.15 and only 6.17 in the subgroup free of IC $(t=-7.294$, $P<0.001$, Cohen's $d=-0.853$ ) (Table 1). Further, hypercholesterinemia, smoking, hazardous drinking, and BMI were also significantly associated with IC. Male sex $\left(\chi^{2}=3.553, P=0.059\right.$, $\mathrm{V}=0.109)$ and age $(t=-1.760, P=0.079$, Cohen's $d=-0.206)$ showed a trend toward being a significant correlate of IC.

Similar findings emerged from the multivariate analyses (Table 2): results of the binary logistic regression analysis $\left(\chi^{2}=76.238, P<0.001\right.$, Cox and Snell $\left.R^{2}=0.224\right)$ indicated

Table 1. Characteristics of the sample stratified by IC status

\begin{tabular}{|c|c|c|c|}
\hline & $\begin{array}{l}\text { Patients with IC } \\
\quad(n=126)\end{array}$ & $\begin{array}{l}\text { Patients without IC } \\
\qquad(n=174)\end{array}$ & Comparison of the groups \\
\hline Sex & & & $\chi^{2}=3.553, P=0.059, \mathrm{~V}=0.109$ \\
\hline Female & $69(54.8)$ & $114(65.5)$ & \\
\hline Male & $57(45.2)$ & $60(34.5)$ & \\
\hline Age (years) & $66.35(8.33)$ & $64.57(8.82)$ & $\begin{array}{c}t=-1.760, P=0.079, d= \\
-0.206\end{array}$ \\
\hline Hypertonia & & & $\chi^{2}=2.668, P=0.102, \mathrm{~V}=0.094$ \\
\hline No & $20(15.9)$ & $41(23.6)$ & \\
\hline Yes & $106(84.1)$ & $133(76.4)$ & \\
\hline Diabetes & & & $\chi^{2}=0.008, P=0.927, \mathrm{~V}=0.005$ \\
\hline No & $79(62.7)$ & $110(63.2)$ & \\
\hline Yes & $47(37.3)$ & $64(36.8)$ & \\
\hline Hypercholesterinemia & & & $\chi^{2}=9.764, P=0.002, \mathrm{~V}=0.180$ \\
\hline No & $43(34.1)$ & $91(52.3)$ & \\
\hline Yes & $83(65.9)$ & $83(47.7)$ & \\
\hline Smoking & & & $\chi^{2}=10.463, P=0.001, \mathrm{~V}=0.187$ \\
\hline No & $83(65.9)$ & $143(82.2)$ & \\
\hline Yes & $43(34.1)$ & $31(17.8)$ & \\
\hline Hazardous drinking & $1.79(2.15)$ & $1.09(1.41)$ & $t=-3.408, P<0.001, d=-0.399$ \\
\hline Body mass index & $28.79(5.07)$ & $30.91(5.59)$ & $t=3.369, P<0.001, d=0.394$ \\
\hline Depression (continuous) & $14.15(9.80)$ & $6.17(9.00)$ & $t=-7.294, P<0.001, d=-0.853$ \\
\hline Depression (categorical) & & & $\chi^{2}=57.299, P<0.001, \mathrm{~V}=0.437$ \\
\hline No & $53(42.1)$ & $146(83.9)$ & \\
\hline Yes & $73(57.9)$ & $28(16.1)$ & \\
\hline
\end{tabular}


Table 2. Predictors of intermittent claudication (Binary logistic regression)

\begin{tabular}{lccr}
\hline & OR & $95 \%$ CI & \multicolumn{1}{c}{. } \\
\hline Sex (male) & 0.931 & $0.515-1.682$ & 0.813 \\
Age & 1.028 & $0.993-1.064$ & 0.115 \\
Smoking & 2.441 & $1.257-4.742$ & 0.008 \\
Hazardous drinking & 1.192 & $1.017-1.397$ & 0.030 \\
Body mass index & 0.958 & $0.908-1.011$ & 0.116 \\
Hypercholesterinemia & 2.174 & $1.260-3.752$ & 0.005 \\
Hypertonia & 1.371 & $0.667-2.818$ & 0.391 \\
Diabetes & 1.246 & $0.709-2.190$ & 0.445 \\
Depression (continuous) & 1.079 & $1.049-1.110$ & $<0.001$ \\
\hline
\end{tabular}

Reference category: IC negative.

OR: odds ratio; CI: confidence interval for the odds ratio.

that depressive symptomatology [OR: 1.08 (1.05-1.11)] was significant in predicting intermittent claudication, even after controlling for its well-known, traditional risk factors such as hypertension, diabetes, hypercholesterinemia, smoking, hazardous drinking, and higher body mass index. Of these traditional risk factors, smoking [OR: 2.44 (1.26-4.74)], hazardous drinking [OR: 1.19 (1.02-1.40)], and hypercholesterinemia [OR: 2.17 (1.26-3.75)] showed a significant, positive relationship with intermittent claudication.

\section{DISCUSSION}

The aim of the present study was to analyze the relationship between depression and intermittent claudication in patients with lower extremity arterial disease. We have found that depressive symptomatology was significant in predicting intermittent claudication, even after controlling for traditional risk factors and variables related to lifestyle factors as smoking, hazardous drinking, and BMI.

Beyond depression, smoking, alcohol consumption, and high cholesterol level were also predictors of intermittent claudication in line with previous studies in this field. Smoking has been found to be a major risk factor of intermittent claudication and thus, LEAD $[3,14]$ and also is the most important risk factor for cardiovascular disorders (CVDs) [15]. Both active and passive smoking causes endothelial dysfunction, enhances platelet aggregation, elevates serum fibrinogen level, and reduces the dilatation of small arteries. On the other hand, smokers have higher serum cholesterol and LDL levels and lower HDL levels when compared to non-smokers [16]. Smoking itself comes with a 2-6 times higher risk of LEAD, and this relationship only rises with the intensity and duration of smoking $[2,17]$. Even after an individual stops smoking, this association persists; however, the negative effects of smoking diminsh considerably beyond 10 years of cessation [18]. At the same time, smoking cessation reduces IC complaints quickly [19].

Previously, hypercholesterinemia was reported to be associated with the prevalence of LEAD in univariate analyses [20]. A prospective, two-decade-long study which examined 51,529 men between the age of 40 and 79 found a strong, graded, independent association with hypercholesterinemia and the prevalence of LEAD [18]. However, HDL cholesterol had a protective 
effect in all epidemiological studies. In a study comparing healthy individuals with patients with LEAD, a high total cholesterol/HDL ratio was strongly associated with the prevalence of symptomatic LEAD [21].

There are only a few studies on the association of LEAD and alcohol consumption as it is not considered as a major risk factor for developing LEAD [3]. Previous studies found that mild or moderate alcohol consumption can reduce the risk of a new cardiovascular event and mortality in patients with ischemic heart disease [22], as well as it can reduce the mortality and incidence of ischemic heart disease [23]. However, this cardioprotective effect diminishes if the mild drinker consumes a bigger amount of alcohol once a month [24]. The same findings were described in the case of intermittent claudication and LEAD [25]. In a Chinese study on diabetic patients, heavy drinking was found to be a risk factor for LEAD in a significant dose-response relationship even after adjusting for age, gender, smoking status, body mass index, weight change, and duration of diabetes [26].

With regard to depressive symptoms, previous studies suggested that the prevalence of depression in patients with LEAD is similar to the prevalence estimated among other patients with CVDs. Cross-sectional estimates of depression prevalence among patients with symptomatic LEAD ranged from 11 to 48\% [27]. In longitudinal studies of subjects who were depressed at baseline, the prevalence of LEAD ranged from 3 to $36 \%$ [27]. Earlier studies suggested that this association between LEAD and depression is rather bidirectional [14]. On one hand, chronic illnesses like LEAD with leg symptoms affect the psychological health and self-esteem of patients [28] but on the other hand, atherosclerotic processes due to inflammatory cytokines can also affect cerebral activity which may result not only in cognitive dysfunctions, but also in emotional and mood fluctuations [29].

Other researchers are of the opinion that both depression and CVDs, including LEAD, are the manifestations of a common risk factor: the subclinical atherosclerosis, also known as "vascular depression" [30]. There are different connecting mechanisms established in the development of depression and vascular disease. Depression itself can lead or worsen an existing vascular disease. Previous studies described a link between elevated serum cortisol levels and the prevalence of depression [31]. Further, depression was reported to be associated with platelet and clotting changes [32], elevated serum lipid levels [33], and an increased level of inflammatory cytokines [34]. Moreover, the serum level of C-reactive protein was found to be a significant correlate to LEAD severity and the prevalence of IC, and predicted further progression [35]. Hypalbuminemia was also a risk factor for the disease [36]. Vascular mechanisms, like hypertension, reduced heart rate variability, thromboembolism with consequent cerebral ischemia in the frontal lobe, and basal ganglia can lead to more severe depressive symptoms [37]. On the other hand, the psychological well-being of patients with intermittent claudication is also affected by their disease and related functional impairment, which can further lead to an unhealthy lifestyle and worsen the modifiable risk factors of IC [38].

At large: three different mechanisms are hypothesized in the underlying pathomechanism, which alone, or more likely in connection, play an important role in the development of atherosclerosis and depression [39]. The disconnection hypothesis is based on the concert of 'disconnection syndromes'. Ischemia caused by vascular mechanisms can lead to the development of white matter lesions contributing to depressive symptomatology by disrupting neural connections among regions regulating mood and cognition [40]. This hypothesis was supported by studies finding that late-life depression was associated with greater white matter 
hyperintensities in specific tracts including the cingulum bundle, uncinate fasciculus, and superior longitudinal fasciculus [41]. Increased cell adhesion molecule expression was also found in these brain areas [32].

The inflammation hypothesis presumes an age and disease-related proinflammatory state in older individuals. A versatile etiology in older age inflammatory conditions (including chronic stress, flu vaccination, chronic infections, and chronic inflammatory diseases like rheumatoid arthritis) can lead to the elevated levels of IL- 6 and IL-1 cytokines, which themselves are predisposing factors in the development of depression [42]. Ageing itself is a proinflammatory state, in which micro- and astroglia-produced cytokines have a key role. These polypeptides regulate neuronal and other cell regeneration and removal thus sustaining homeostasis [43]. This hypothesis raises the possible role of anti-inflammatory medications in the treatment of depression, independently of any vascular risk factors [39].

Finally, according to the hypoperfusion hypothesis, vascular dysregulation is common in late life depression [44] and cerebral blood flow reductions can impair regional brain function, contributing to affective and cognitive symptoms.

Limitations of the present study also need to be acknowledged. First, the cross-sectional design of the present study does not allow firm conclusions to be drawn regarding the direction of the relationship between IC and depression. Second, recruitment of participants was not systematic or random and occurred in the primary care setting making it difficult to evaluate the generalizability of the findings.

\section{CONCLUSIONS}

We have found that depressive symptomatology was significant in predicting intermittent claudication, even after controlling for traditional risk factors. The early recognition of both IC and depressive symptomatology are crucial in the management of lower extremity arterial disease. Our results underscore the importance of a multidisciplinary approach that focuses on supporting health-related behavioral changes (cf. diet, exercise, and substance use) and managing mental health symptoms when providing care for individuals suffering from IC.

\section{ACKNOWLEDGMENTS}

While working on this manuscript, financial support was provided to the first author by Semmelweis University (grant \# EFOP-3.6.3-VEKOP-16-2017-00009). The authors also wish to thank Tyler Szusecki for the proofreading of the manuscript.

\section{REFERENCES}

1. Járai Z. Érbetegségek [Vascular diseases]. In: Tulassay Z, editor. A belgyógyászat alapjai [Principles of internal medicine]. Budapest: Medicina Kiadó; 2010, pp. 711-2. 
2. Fowkes FGR, Rudan D, Rudan I, Aboyans V, Denenberg JO, McDermott MM, et al. Comparison of global estimates of prevalence and risk factors for peripheral artery disease in 2000 and 2010: a systematic review and analysis. Lancet 2013; 382: 1329-40.

3. Aboyans V, Ricco JB, Bartelink MEL, Björck M, Brodmann M, Cohnert T, et al. 2017 ESC guidelines on the diagnosis and treatment of peripheral arterial diseases, in collaboration with the European society for vascular surgery (ESVS): document covering atherosclerotic disease of extracranial carotid and vertebral, mesenteric, renal, upper and lower extremity arteries. Endorsed by: the European stroke organization (ESO) the task force for the diagnosis and treatment of peripheral arterial diseases of the European society of cardiology (ESC) and of the European society for vascular surgery (ESVS). Eur Heart J 2018; 39: 763-816.

4. Tóth-Vajna Z, Tóth-Vajna G, Gombos Z, Szilágyi B, Járai Z, Berczeli M, et al. Screening of peripheral arterial disease in primary health care. Vas Health Risk Manag 2019; 15: 355-63.

5. Weitz JI, Byrne J, Clagett GP, Farkouh ME, Porter JM, Sackett DL, et al. Diagnosis and treatment of chronic arterial insufficiency of the lower extremities: a critical review. Circulation 1996; 94: 3026-49.

6. Sliwka A, Furgal M, Maga P, Drelicharz L, Mika P, Włoch T, et al. The role of psychopathology in perceiving, reporting and treating intermittent claudication. A systematic review. Int Angiol 2018.

7. Ragazzo L, Puech-Leao P, Wolosker N, de Luccia N, Saes G, Ritti-Dias RM, et al. Symptoms of anxiety and depression and their relationship with barriers to physical activity in patients with intermittent claudication. Clinics 2021; 76: e1802.

8. Siennicki-Lantz A, André-Petersson L, Wollmer P and Elmståhl S. Depressive symptoms, atherosclerotic burden and cerebral blood flow disturbances in a cohort of octogenarian men from a general population. BMC Psychiatry 2013; 13: 347.

9. Wong SY, Woo J, Hong AW, Leung JC and Leung PC. Clinically relevant depressive symptoms and peripheral arterial disease in elderly men and women. Results from a large cohort study in Southern China. J Psychosom Res 2007; 63: 471-6.

10. McDermott MM, Guralnik JM, Tian L, Kibbe MR, Ferrucci L, Zhao L, et al. Incidence and prognostic significance of depressive symptoms in peripheral artery disease. J Am Heart Assoc 2016; 5:e002959.

11. Leng GC and Fowkes FG. The Edinburgh Claudication Questionnaire: an improved version of the WHO/ Rose Questionnaire for use in epidemiological surveys. J Clin Epidemiol 1992; 45: 1101-9.

12. Rózsa S, Szádóczky E and Füredi J. A Beck depresszió kérdőív rövidített változatának jellemzői hazai mintán [Psychometric properties of the Hungarian version of the shortened Beck Depression Inventory]. Psychiatr Hung 2001; 16: 384-402.

13. Máttyássy A, Kelemen O. Alkohol okozta mentális és viselkedési zavarok [Mental and behavioral disorders due to use of alcohol]. In: Németh A, editor. A pszichiátria rövidített kézikönyve [Shorter Handbook of Psychiatry]. Budapest: Medicina Kiadó; 2011, pp. 187-212.

14. Criqui MH, Denenberg JO, Langer RD and Fronek A. The epidemiology of peripheral arterial disease: importance of identifying the population at risk. Vasc Med 1997; 2: 221-6.

15. Banks E, Joshy G, Korda RJ, Stavreski B, Soga K, Egger S, et al. Tobacco smoking and risk of 36 cardiovascular disease subtypes: fatal and non-fatal outcomes in a large prospective Australian study. BMC Med 2019; 17 : 128.

16. Taylor BV, Oudit GY, Kalman PG and Liu P. Clinical and pathophysiological effects of active and passive smoking on the cardiovascular system. Can J Cardiol 1998; 14: 1129-39.

17. Price JF, Mowbray PI, Lee AJ, Rumley A, Lowe GD and Fowkes FG. Relationship between smoking and cardiovascular risk factors in the development of peripheral arterial disease and coronary artery disease: Edinburgh Artery Study. Eur Heart J 1999; 20: 344-53.

18. Joosten MM, Pai JK, Bertoia ML, Rimm EB, Spiegelman D, Mittleman MA, et al. Associations between conventional cardiovascular risk factors and risk of peripheral artery disease in men. JAMA 2012; 308: $1660-7$. 
19. Kannel WB and Shurtleff D. The Framingham Study. Cigarettes and the development of intermittent claudication. Geriatrics 1973; 28: 61-8.

20. Meijer WT, Grobbee DE, Hunink MGM, Hofman A and Hoes AW. Determinants of peripheral arterial disease in the elderly: the Rotterdam study. Arch Intern Med 2000; 160: 2934-8.

21. Ridker PM, Stampfer MJ and Rifai N. Novel risk factors for systemic Atherosclerosis A comparison of C-reactive protein, fibrinogen, homocysteine, lipoprotein(a), and standard cholesterol screening as predictors of peripheral arterial disease. JAMA 2001; 285: 2481-5.

22. Mukamal KJ, Maclure M, Muller JE, Sherwood JB and Mittleman MA. Prior alcohol consumption and mortality following acute myocardial infarction. JAMA 2001; 285: 1965-70.

23. Rimm EB, Williams $\mathrm{P}$, Fosher K, Criqui $\mathrm{M}$ and Stampfer MJ. Moderate alcohol intake and lower risk of coronary heart disease: meta-analysis of effects on lipids and haemostatic factors. BMJ 1999; 319: 1523-8.

24. Bagnardi V, Zatonski W, Scotti L, La Vecchia C and Corrao G. Does drinking pattern modify the effect of alcohol on the risk of coronary heart disease? Evidence from a meta-analysis. J Epidemiol Commun H 2008; 62: 615-9.

25. Wakabayashi I and Sotoda Y. Alcohol drinking and peripheral arterial disease of lower extremity. Nihon Arukoru Yakubutsu Igakkai Zasshi 2014; 49: 13-27.

26. Yang S, Wang S, Yang B, Zheng J, Cai Y and Yang Z. Alcohol consumption is a risk factor for lower extremity arterial disease in Chinese patients with T2DM. J Diabetes Res 2017; 2017: 8756978.

27. Brostow DP, Petrik ML, Starosta AJ and Waldo SW. Depression in patients with peripheral arterial disease: a systematic review. Eur Jour Cardiovasc Nur 2017; 16: 181-93.

28. Kentson M, Tödt K, Skargren E, Jakobsson P, Ernerudh J, Unosson M, et al. Factors associated with experience of fatigue, and functional limitations due to fatigue in patients with stable COPD. Ther Adv Respir Dis 2016; 10: 410-24.

29. Baune BT, Caniato RN, Garcia-Alcaraz MA and Berger K. Combined effects of major depression, pain and somatic disorders on general functioning in the general adult population. Pain 2008; 138: 310-7.

30. Alexopoulos GS, Meyers BS, Young RC, Campbell S, Silbersweig D and Charlson M. 'Vascular depression' hypothesis. Arch Gen Psychiat 1997; 54: 915-22.

31. Hinkelmann K, Muhtz C, Dettenborn L, Agorastos A, Moritz S, Wingenfeld K, et al. Association between cortisol awakening response and memory function in major depression. Psychol Med 2013; 43: 2255-63.

32. Thomas AJ, Kalaria RN and O'Brien JT. Depression and vascular disease: what is the relationship? J Affect Disord 2004; 79: 81-95.

33. Oh J and Kim TS. Serum lipid levels in depression and suicidality: the Korea National health and Nutrition examination survey (KNHANES) 2014. J Affect Disord 2017; 213: 51-8.

34. Dantzer R, O'Connor JC, Freund GG, Johnson RW and Kelley KW. From inflammation to sickness and depression: when the immune system subjugates the brain. Nat Rev Neurosci 2008; 9: 46-56.

35. Tzoulaki I, Murray GD, Lee AJ, Rumley A, Lowe GD and Fowkes FG. C-reactive protein, interleukin-6, and soluble adhesion molecules as predictors of progressive peripheral atherosclerosis in the general population: Edinburgh Artery Study. Circulation 2005; 112: 976-83.

36. Jong IC, Tsai HB, Lin CH, Ma TL, Guo HR, Hung PH, et al. Close correlation between the ankle-brachial index and symptoms of depression in hemodialysis patients. Int Urol Nephrol 2017; 49: 1463-70.

37. Taylor CB. Depression, heart rate related variables and cardiovascular disease. Int J Psychophysiol 2010; 78: $80-8$.

38. Grenon SM, Cohen BE, Smolderen K, Vittinghoff E, Whooley MA and Hiramoto J. Peripheral arterial disease, gender, and depression in the Heart and Soul Study. J Vasc Surg 2014; 60: 396-403. 
39. Taylor WD, Aizenstein HJ and Alexopoulos GS. The vascular depression hypothesis: mechanisms linking vascular disease with depression. Mol Psychiatr 2013; 18: 963-74.

40. Alexopoulos GS. Frontostriatal and limbic dysfunction in late-life depression. Am J Geriatr Psychiat 2002; 10: 687-95.

41. Taylor WD, Zhao Z, Ashley-Koch A, Payne ME, Steffens DC, Krishnan RR, et al. Fiber tract-specific white matter lesion severity Findings in late-life depression and by AGTR1 A1166C genotype. Hum Brain Mapp 2013; 34: 295-303.

42. Godbout JP and Johnson RW. Age and neuroinflammation: a lifetime of psychoneuroimmune consequences. Immunol Allergy Clin 2009; 29: 321-37.

43. Alexopoulos GS and Morimoto SS. The inflammation hypothesis in geriatric depression. Int J Geriatr Psych 2011; 26: 1109-18.

44. Greenstein AS, Paranthaman R, Burns A, Jackson A, Malik RA, Baldwin RC, et al. Cerebrovascular damage in late-life depression is associated with structural and functional abnormalities of subcutaneous small arteries. Hypertension. 2010; 56: 734-40.

Open Access. This is an open-access article distributed under the terms of the Creative Commons Attribution 4.0 International License (https://creativecommons.org/licenses/by/4.0/), which permits unrestricted use, distribution, and reproduction in any medium, provided the original author and source are credited, a link to the CC License is provided, and changes - if any - are indicated. (SID_1) 